\title{
1 Perturbation of GABA Biosynthesis Links Cell Cycle to \\ 2 Control Arabidopsis thaliana Leaf Development
}

3 Yaxin Gong, Han Yue, Yu Xiang, Guanghui Yu*

4 Hubei Provincial Key Laboratory for Protection and Application of Special Plants in

5 Wuling Area of China, Engineering Research Centre for the Protection and Utilization

6 of Bioresource in Ethnic Area of Southern China, College of Life Sciences,

7 South-Central University for Nationalities, Wuhan 430074, China

8

\section{* Correspondence:}

Guanghui Yu

yuguanghui@scuec.edu.com

Keywords: Arabidopsis thaliana; CDKA;1; endoreplication; GABA; Reactive Oxygen Species

Running title: Endoreplication response to GABA deficit

\section{Abstract}

To investigate the molecular mechanism underlying increasing leaf area in $\gamma$-Aminobutyric acid (GABA) biosynthetic mutants, the first pair of true leaves of GABA biosynthetic mutants was measured. The results showed that the leaf blade area in GABA biosynthetic mutants was larger than that of the wild type to different extents, and the area of the leaf epidermal cells in mutants was larger than that of the wild type. DNA polyploid analysis showed that polyploid cells in GABA biosynthetic mutants were appearing earlier and more abundant than in the wild type. To check the correlation between cell size and endoreplication, the expression of factors involving endocycles, including D-type cyclin gene (CYCD3;1, CYCD3;2, CYCD3;3, and $C Y C D 4 ; 1)$ and kinase $C K D A ; 1$, were analysed by qRT-PCR. The results showed that $C K D A ; 1$ in GABA biosynthetic mutants was downregulated, and four types of $C Y C D$ s showed different expression patterns in different GABA biosynthetic mutants. Inconsistent with this result, for CCS52A (CELL CYCLE SWITCH 52A) (controlling the endocycle entry) in gad2 and gadl/gad2 mutants, the expression of CCS52A2 was significantly higher than that in the wild type. The expression of SIM (SIAMESE) and SMR (SIAMESE-RELATED), which inhibit kinase activity, were also upregulated compared with the control. To further study the possible potential relationship between GABA metabolism and endoreplication, we analysed the reactive oxygen species (ROS) levels in guard cells using ROS fluorescent probes. ROS levels were significantly higher in GABA biosynthetic mutants than the control. All results indicated that cyclin, the cyclin-dependent kinase, and its inhibitory protein were 


\section{Endoreplication response to GABA deficit}

38 coordinated to participate in endoreplication control at the transcription level in the

39 leaves of GABA biosynthetic mutant Arabidopsis.

40 


\section{Endoreplication response to GABA deficit}

\section{Contribution to the field statement}

$\gamma$-Aminobutyric acid (GABA) metabolic pathway plays a dual role in plant development. This research investigated the perturbation of GABA biosynthesis on Arabidopsis leave endoreplication for the first time. In the GABA biosynthetic mutants, many genes, participating in cell division regulation, are coordinately transcriptionally expressed to trigger the onset and maintenance of endoreplication, and this led to the cell expansion and the increase leaf blade area. However, this initiation of endoreplication links with the decrease of endogenous GABA level and the increase Reactive oxygen species (ROS). This may be a compensation mechanism to adapt to abnormal GABA level in plant leaf development. Present evidence provided hypothesized that the normal GABA level in plant leaf development plays a brake to inhibit the immature cell expansion and differentiation, and this negative regulation functions a guarantee mechanism to watchdog the normal leaf development. In all, this contribution provides an updated perspective on the role of GABA in plant development.

\section{Introduction}

$\gamma$-Aminobutyric acid (GABA) is a four-C, non-protein component amino acid commonly found in organisms and is prevalent in bacteria, plants, and vertebrates (Seifikalhor et al., 2019). The precursor of GABA synthesis is L-glutamic acid (Glu), which is catalysed by glutamate decarboxylase (GAD) in cytoplasm. The Arabidopsis genome has five genes encoding GAD named GAD1-5. The oxidative metabolism of GABA occurs in mitochondria and entry is mediated by a GABA permease (Michaeli et al., 2011). In mitochondria, using $\alpha$-ketoglutarate or pyruvate as an amino acceptor, GABA is catalysed by GABA transaminase (GABA-T) to produce glutamic acid (Glu) or Alanine (Ala) and succinic semialdehyde (SSA), respectively. SSA is oxidized by SSA dehydrogenase (SSADH) to succinic acid (SucA), and then SucA enters the tricarboxylic acid (TCA) cycle for further metabolism. This metabolic pathway is referred to as the GABA shunt. Under hypoxic or high-light conditions, SSA can be reduced to gamma-hydroxybutyrate (GHB) by SSA reductase (SSR, also known as GHB dehydrogenase) in the cytoplasm, mitochondria, and chloroplasts (Allan et al., 2008). Previous studies have reported that unique cytosolic and plastid glyoxylate reductase isoforms in Arabidopsis are known as GLYR1 and atGLYR2, respectively, and they catalyse the conversion of SSA to GHB and glyoxylic acid to glycolic acid via an NADPH-dependent reaction (Brikis et al., 2017). The balance of the redox state was maintained by the accumulation of GHB and the reduction of SSA via the GABA shunt.

GABA biosynthesis and accumulation from the glutamic acid pathway and its metabolism are at the junction of $\mathrm{N}$ and $\mathrm{C}$ metabolism, providing a useful metabolic substrate for the TCA cycle, electron transport chain, and $\mathrm{C}$ skeleton, which are 


\section{Endoreplication response to GABA deficit}

involved in the balancing of C:N metabolism (Jacoby et al., 2011). It is generally believed that GABA metabolism is considered to be involved in metabolic signalling, which plays a dual role in plant development, including both metabolic and signal regulation (Häusler et al., 2014; Ramesh et al., 2017; Podlešáková et al., 2019). In addition, aldehyde chemical groups (i.e. $\mathrm{H}-\mathrm{C}=\mathrm{O}$ ) produced by $\mathrm{GABA}$ biosynthesis and metabolic pathways in plants have high molecular activity, and aldehydes accumulated under stressed conditions are highly toxic and can react with DNA, lipids of oxidative membranes, and modified proteins, or affect the transcription of stress-related genes, leading to cellular and ontogenetic problems in plants. Previous studies have reported that GABA metabolism regulates leaf pattern morphogenesis. The SSADH gene is involved in the formation of the paraxial-abaxial (upper-lower) leaf model in Arabidopsis thaliana (Toyokura et al., 2011; 2012). Mutation of enf1 (enlarged fil expression domain1) alters the expression pattern of the FIL (YABBY1, FILAMENTOUS FLOWER) gene, which is characteristic of meristem and organs in $A$. thaliana (Sawa et al., 1999), on the abaxial surface of leaf primordium (Sawa et al., 1999; Siegfried et al., 1999). However, here is a dearth of research on the role of GABA biosynthesis in the leaf development of $A$. thaliana. In the present study, GABA biosynthetic mutants, gad1, gad2, and gadl/gad2 were examined to explore the molecular mechanism underlying the GABA negative feedback that regulates leaf cell endoreplication during leaf development. Our findings will provide evidence for further understanding the role of GABA in plant development.

\section{Materials and methods}

\subsection{Experimental Materials}

A. thaliana Col wild-type seeds, Col ecotype gad1 mutant, gad2 mutant, and gad1/gad2 double mutant were provided by Prof. Barry Shelp (University of Guelph, Canada). The seeds of the wild type and mutants were sterilized for $\sim 2 \mathrm{~h}$ in a sealed container with chlorine gas, and then inoculated on MS solid medium and synchronized for $3 \mathrm{~d}$ at $4{ }^{\circ} \mathrm{C}$. After synchronization, the plate was taken out and placed in greenhouse under a photoperiod of $16 / 8 \mathrm{~h} \mathrm{light} /$ dark and incubated at $22{ }^{\circ} \mathrm{C}$.

\subsection{Measurement of leaf blade area}

From the $4^{\text {th }}$ day after $A$. thaliana seedlings being transferred to the greenhouse, their growth condition was photographed every $24 \mathrm{~h}$ with a Brinno time-lapse camera (TLC100) at a fixed distance to record the leaf blade area.

\subsection{Microscopic observation and measurement of cell area}

From the $7^{\text {th }}$ day after $A$. thaliana seedlings being transferred to the greenhouse, the first pair of true leaves was collected daily, the leaf abaxial epidermis located $25 \%$ and $75 \%$ from the distance between the tip and the base of the leaf blade was photocopied with nail polish, and then photographed using an Olympus DP80 microscope, and the area was calculated with the software that came with the microscope. Under the microscope, a certain area of the epidermis was confined to count the number of cells, and then the average cell area was calculated.

\subsection{DNA ploidy analysis}




\section{Endoreplication response to GABA deficit}

Approximately two or three leaves at the young stage or one or two leaves at the middle and late leaf developmental stages were chopped with a razor blade in nuclei extraction buffer (CyStain ${ }^{\circledR}$ UV Precise P, Sysmex Partec), and then transferred to the staining buffer (CyStain ${ }^{\circledR}$ UV Precise P, Sysmex Partec) according to the manufacturer's instructions. The ploidy level of DNA in leaf cells was determined using a CyFlow Ploidy Analyser (Sysmex Partec).

\section{5 qRT-PCR analysis}

Total RNA from A. thaliana leaves was extracted by AxyPrep Multisource Total RNA Miniprep Kit (Axygen Science, Inc). Reverse transcription was performed by Goldenstar RT6 Gene Synthesis Kit (Tingke Biotechnology Co., Ltd.) with a reverse transcription reaction system of $20 \mu \mathrm{L}$. qRT-PCR analysis was performed by MyGo Pro qPCR System (IT-IS Life Science Ltd.). The gene isoprenyl diphosphate delta isomerase II (IPP2, AT3G02780) was selected as the internal reference gene according to previous research (Fung-Uceda et al., 2018). The primers of the genes involved in cell cycle regulation, endocycle initiation, progression, and exit are listed in the supporting materials (Table S1).

\subsection{In vivo reactive oxygen species imaging}

For GC reactive oxygen species (ROS) staining, H2DCF-DA stock solution (10 $\mathrm{mmol} / \mathrm{L}$ stock in Dimethyl Sulfoxide) was diluted in deionized water to yield a final concentration of $6.25 \mu \mathrm{mol} / \mathrm{L}$ with a final dimethyl sulfoxide concentration of $0.0125 \%$ (v/v) (Watkins et al., 2017). Epidermal strips were peeled with adhesive tape and directly stained for $30 \mathrm{~min}$ in the above solution. After rinsing with deionized water for $5 \mathrm{~min}$, images were taken by Olympus DP80 fluorescent microscopy. The intensity of coloration was quantified using ImageJ software (National Institutes of Health, USA).

\subsection{Statistical analyses}

Data are expressed as averages \pm standard error (SE). Experiments were conducted with two or three independent replicates. One-way ANOVA was employed using SPSS 20.0.

\section{Results}

\subsection{The leaf blade area of the GABA biosynthetic mutant was larger than that of the wild type}

At the early stage of leaf development ( $4^{\text {th }}$ day after stratification), there was no significant difference in the area of the first pair of true leaves between the wild-type and GABA biosynthetic mutants (Figure 1). As time progressed, the area of the mutant leaves increased more rapidly than that of the wild type. Around the $8^{\text {th }}$ day, the leaf area of the first pair of true leaves in the wild type was about $1.8 \mathrm{~mm}^{2}$, and the first pair of true leaves in gadl and gad2 mutants was about $2.4 \mathrm{~mm}^{2}$, at 1.3 -fold that of the wild type, and that of the gadl/gad 2 mutants was about $3.2 \mathrm{~mm}^{2}$ with 1.8 -fold that of the wild type (Figure 1). The leaf area between the GABA biosynthetic mutants and wild type was significantly different $(P<0.05)$. 


\section{Endoreplication response to GABA deficit}

\subsection{Cell size in GABA biosynthetic mutants was larger than those of the wild type}

To determine the reasons for the leaf area in GABA biosynthetic mutants being larger than that in the wild type, we compared the area of leaf epidermal cells. The average cell area in the epidermis of the first pair of true leaves of the wild type was about $2700 \mu \mathrm{m}^{2}$ at the $8^{\text {th }}$ day after stratification (Figure 2). The average cell area of the epidermis of the first pair of leaves of gadl and gad2 mutants was $\sim 3200 \mu \mathrm{m}^{2}$, 1.2 -fold that of the wild type $(P<0.05)$. The average cell area of the epidermis of the first pair of true leaves in gadl/gad2 mutants was $\sim 3800 \mu \mathrm{m}^{2}$, and was 1.4 -fold that of the wild type with significant differences $(P<0.05)$ (Figure 2$)$.

\subsection{The polyploidy in GABA biosynthetic mutant leaf occurred earlier and higher than that of the wild type}

The correlation between cell size and DNA ploidy level (Matsunaga et al., 2013) prompted us to explore whether the cell size of GABA biosynthetic mutants is related to DNA polyploidy level. On the $7^{\text {th }}$ day of leaf development after stratification, the cells in the first pair of true leaves in wild-type $A$. thaliana were mostly diploid and tetraploid, indicating that leaf cells mainly divided at this stage (Figure 3A). However, leaf cells in gad1, gad2, and gadl/gad2 mutants appeared to be in different proportions of 8-ploid cells except the diploid and tetraploid cells (Figure 3B). The appearance of 8-ploid cells in leaves is a marker of endoreplication. On the $8^{\text {th }}$ day of leaf development, 8-ploid cells were not found in wild-type A. thaliana, and the proportion of octoploid cells in three kind of GABA-biosynthetic mutants increased further (Figure 3B).

To further confirm the relationship between cell enlargement and cell ploidy level, we compared the cell ploidy level in the middle and late leaf development stages $\left(21^{\text {st }}\right.$ day after stratification). The proportion of octoploid cells in the wild type was about $18 \%$ (Figure 3C). However, the proportion of the octoploid cells in gadl, gad2, and gadl/gad 2 mutants was about $30-40 \%$, which was significantly higher than that in the wild type (Figure 3C).

Overall, at the early stage of leaf development (7-8 $8^{\text {th }}$ day after stratification), the 8-ploid cells were only detected in the GABA biosynthetic mutants (8-ploid cells in gadl and gad2 mutants was 3-5\%, and that in gad1/gad2 double mutants was about $5-9 \%$ ) (Figure 3D). At the late stage of leaf development $\left(21^{\text {st }}\right.$ day after stratification), the proportion of 8-ploid cells in wild-type leaves was also detected; however, its level was significantly lower than that in gad mutants (Figure 3D).

\subsection{Type-D cyclin genes involved in endocycle regulation in GABA biosynthetic mutants}

Considering that endoreplication is a special form of cell division (De Veylder et al., 2011) and is the reason for cell polyploidy (Matsunaga et al., 2013), type-D relative gene participation in cell cycle regulation was analysed by qRT-PCR.

CYCD3;1 (At4g34160) is a key component to balance cell proliferation/division and endoreplication (Dewitte et al., 2007). Downregulation of CYCD3;1 can lead to 


\section{Endoreplication response to GABA deficit}

endoreplication, and its overexpression can cause excessive cell proliferation and inhibit cell differentiation (Dewitte et al., 2003). qRT-PCR confirmed that the expression of $C Y C D 3 ; 1$ was significantly downregulated in GABA biosynthetic mutants (Figure 4). In gadl and gad2 single mutants, the relative expression of CYCD3; 1 was about 0.2 -fold that of the wild type $(P<0.01)$, and in gadl/gad2 double mutants, the relative expression of $C Y C D 3 ; 1$ was about 0.1 -fold that of the wild type $(P<0.01)$ (Figure 4$)$, indicating that blocking GABA synthesis inhibited the expression of $C Y C D 3 ; 1$.

CYCD3;2 (At5g67260) and CYCD3;3 (At3g50070) participate in the symmetrical division of guard mother cells and guard cells (GCs) in the late stomatal lineage development (Yang et al., 2014). In the gadl mutant, the expression of CYCD3;2 was significantly downregulated $(P<0.05)$; in the gad2 and gadl/gad2 mutants, the relative expression of $C Y C D 3 ; 2$ was about 0.6 -fold that of the wild type with significant differences $(P<0.01)$ (Figure 4). Similarly, the expression of CYCD3;3 in the gadl mutant was about 0.3 -fold that of the wild type $(P<0.01)$, and in the gad 2 and $\mathrm{gad} 1 / \mathrm{gad} 2$ mutants, the expression of $C Y C D 3 ; 3$ was 0.7 and 0.5 -fold that of the wild type, respectively $(P<0.05)$ (Figure 4). CYCD4;1 (At5g65420) could activate the cell cycle of root apical meristem (Masubelele et al., 2005), and the expression of CYCD4;1 in the gad2 mutant was significantly downregulated $(P<0.05)$, and in the gadl and gadl/gad2 mutants the relative expression of $C Y C D 4 ; 1$ decreased to become the most significantly different to that of the wild type $(P<0.01)$ (Figure 4$)$.

\subsection{The expression of $C D K A ; 1$ in GABA biosynthetic mutants was significantly downregulated}

CDKA;1 (At3g48750) is one of the core components of cell cycle regulation, mainly controlling the transition of the G1/S and G2/M mitotic phase (Nowack et al., 2012). Inhibition of its activity can block mitosis to initiate leaf cell endoreplication (Verkest et al., 2005). The expression of $C D K A ; 1$ in GABA biosynthetic mutants was significantly lower than that in the wild type $(P<0.05)$. These results indicated that blocking GABA synthesis is linked with the decreased expression of $C D K A ; 1$ (Figure $5)$.

The transcription factor E2Fa (At2g36010) stimulates cell proliferation and delayed differentiation (Boudolf et al., 2004). In the gadl and gad2 mutants, the expression of $E 2 F a$ was significantly downregulated $(P<0.05)$. In gad1/gad2, the level of $E 2 F a$ was 0.2 -fold that in the wild type $(P<0.01)$ (Figure 5$)$.

\subsection{Different expression patterns of CCS52A2 and CDC6 were observed in} GABA synthetic mutants

CCS52A2 (CELL CYCLE SWITCH52, At4g11920) encodes a ubiquitin ligase regulating cell cycle division phase $(\mathrm{M})$ and a substrate-specific activator of anaphase promotion complex/cyclosome (Fülöp et al., 2005). Inhibition of kinase activity after CCS52A2 expression and enhancement of its activity are prerequisites for endoreplication (Heyman et al., 2017; Umeda et al., 2019). Mutations in the CCS52 gene resulted in delayed endoreplication, and its overexpression resulted in increased DNA ploidy levels (Heyman et al., 2017). In the gadl mutant, the relative expression of CCS52A2 was not different from that of the wild type; however, in the gad2 and 


\section{Endoreplication response to GABA deficit}

gadl/gad2 mutants, the expression of CCS52A2 was significantly higher than that of the wild type $(P<0.05)$ (Figure 6$)$.

CDC6 (At2g29680) encodes a homolog of cell division regulatory protein 6 (Castellano et al., 2001), which is a license gene for DNA replication (Fung-Uceda et al., 2018). CDC6 participates in the initiation of DNA replication and is an important factor for maintaining endoreplication. The ectopic expression of CDC6 can increase the ploidy level caused by endoreplication (Castellano et al., 2001; 2004). In the gadl mutant, the relative expression of $C D C 6$ was 1.7 -fold as much as that in the wild type $(P<0.05)$ (Figure 6). The expression of $C D C 6$ in the gad2 mutant was about 3 -fold that in the wild type $(P<0.01)$, and the expression of $C D C 6$ in the gad1/gad2 double mutant was about 8 -fold that in the wild type $(P<0.01)$ (Figure 6$)$.

\subsection{The expression of SIAMESE and SIAMESE-RELATED in GABA biosynthetic mutants was significantly up-regulated}

SIAMESE (SIM, At5g04470) is an inhibitory protein of cyclin-dependent kinase and a regulator of mitotic inhibition and endoreplication (Churchman et al., 2006). Overexpression of SIM results in dwarfing of plants, serrated leaves, and cells with higher nuclear DNA content (Churchman et al., 2006). The relative expression of the SIM in gadl single mutant is about twice that of the wild type $(P<0.05)$, in the gad2 single mutant is about 4 -fold that of the wild type $(P<0.05)$, and in the gad1/gad2 double mutant is about 7 -fold that of the wild type $(P<0.01)$ (Figure 7).

Most components of the SIAMESE-RELATED (SMR) gene family function in mitosis inhibition and endocycle promotion (Yi et al., 2014; Kumar et al., 2015; Dubois et al., 2018). In the chosen genes, the expression of SMR1 (At3g10525) in gadl and gad2 mutants was not different to that of the wild type. In the gadl/gad2 mutants, its expression is 1.5 -fold that of the wild type $(P<0.05)$ (Figure 7). However, the expression of other components, SMR2 (At1g08180), SMR5 (At1g07500), and SMR8, was markedly different to that of the wild type (Figure 7). The expression of SMR2 in gad1, gad2, and gad1/2 reached 5-, 6-, and 11-fold of that in the wild type, respectively $(P<0.01)$. Similarly, the expression of SMR5 in gad1, gad2, and gad1/2 reached 3-, 5- $(P<0.05)$, and 17-fold that in the wild type $(P<0.01)$, respectively, and the expression of SMR8 in gad1, gad2, and gad1/2 reached 4-, 4- $(P<0.05)$, and 6 -fold that in the wild type $(P<0.01)$, respectively.

\subsection{The level of ROS in leaves of GABA biosynthetic mutant was higher than that of the wild type}

The fact that redox regulates cell proliferation and the cell cycle (Schippers et al., 2016), and GABA could scavenge ROS (Liu et al., 2011; Seifikalhor et al., 2019), led us to postulate that ROS levels in GABA biosynthetic mutants could be increased. Imaging of H2DCFDA (DCFH-DA; 2', 7'-Dichlorodihydrofluorescein diacetate) with the fluorescent probe of ROS showed that the average ROS level intensity in GCs of gad mutants was higher than that in the wild type $(P<0.05)$ (Figure 8$)$. These results suggest that GABA synthetic mutants are indeed correlated with ROS accumulation.

\section{Discussion}




\section{Endoreplication response to GABA deficit}

The GABA metabolic pathway plays a dual role during plant development, including metabolic and signal regulation (Bown \& Shelp, 2016; Seifikalhor et al., 2019). Abnormal GABA biosynthesis and metabolism have important effects on plant development (Baum et al., 1996; Palanivelu et al., 2003; Renault et al., 2013). The expression of the Petunia GAD gene, which lacked the calmodulin-binding domain in transgenic tobacco, resulted in abnormal plant development, which was shorter and more branched than that of normal plants (Baum et al., 1996). In the Arabidopsis GABA-T (pop2-1) mutant, the growth of pollen tubes could not accurately target the ovule sac in the pistils (Palanivelu et al., 2003). The molecular mechanism was related to the destruction of the gradient distribution of GABA in the stigma of the pistils (Palanivelu et al., 2003). Furthermore, the growth retardation in hypocotyl epidermal cells and root cortex cells is related to the limitation of cell elongation (Renault et al., 2011), and inadequate expression of $G A B A-T$ may lead to developmental defects in roots and hypocotyls and composition change in cell walls (Renault et al., 2013).

In the present study, the molecular mechanism underlying leaf-area enlargement in GABA biosynthetic mutants was investigated. The growth of plant leaves is largely limited by the development of the epidermis. Polyploidy in pavement cells is strongly correlated with cell size $(P<0.01)$ (Melaragno et al., 1993). We confirmed that the larger leaf area and cell size in GABA biosynthetic mutants (Figures 1,2) was related to much higher percentages of polyploid cells in GABA biosynthetic mutant leaves, which occurred earlier and in higher abundance than that of the wild-type leaf cells (Figure 3).

Endoreplication is a special kind of cell division (De Veylder et al., 2011), and the essence of endoreplication is to maintain CDK activity below the threshold that triggers mitosis (De Veylder et al., 2011). During leaf development of $A$. thaliana, the decrease in transcription levels of mitotic CDK and cyclin genes resulted in endoreplication (Beemster et al., 2006). Consistent with these results, the qRT-PCR analysis confirmed that the type-D cyclin genes (CYCD3; 1, CYCD3;2, CYCD3;3, and $C Y C D 4 ; 1)$ were differently downregulated in GABA biosynthetic mutants, and the expression of $C D K A ; 1$ exhibited a decreasing expression trend (Figures 4, 5).

Other factors interrelated with endoreplication regulation, from endoreplication initiation, progression, and maintenance, and exit (Breuer et al., 2014), synergistically regulate the occurrence of endoreplication in the leaves of GABA biosynthetic mutants. CCS52A (CELL CYCLE SWITCH 52A) plays an important role in cell cycle exit and endoreplication entry (Lammens et al., 2009; Vlieghe et al., 2005). The concentration of CCS52A in mitotic cells remains below a critical threshold to prevent immaturely initiating endoreplication (Lammens et al., 2009; Vlieghe et al., 2005). In the gad2 and gadl/gad2 mutants, the relative expression of CCS52A2 was significantly higher than that of the wild type (Figure 6). The expression of cyclin-dependent kinase inhibitor SIM (SIAMESE) and its SMR (SIAMESE-RELATED) was significantly higher than that of the control (Figure 7). These results demonstrated that the endoreplication regulators, including cyclin, cyclin-dependent kinase, and kinase inhibitor, at the transcriptional level, all harmoniously contributed to the regulation of endoreplication in mutants.

It is worth noting that SMR5, a member of SMR (SIAMESE-RELATED), is an ROS-induced gene, which is more highly expressed in GABA biosynthetic mutants 


\section{Endoreplication response to GABA deficit}

(3-17-fold that of the control) (Figure 7). ROS is an important signalling molecule regulating leaf development and is involved in triggering endoreplication (Schippers et al., 2016). Previous evidence proved that exogenous GABA could scavenge ROS (Liu et al., 2011), and the GABA level in mutants was much lower than that in the wild type (Figure S1); thus, we speculated that the perturbation of GABA biosynthesis may be intrinsically linked with the ROS level. Detection using an ROS fluorescence probe confirmed that the level of ROS in GCs of GABA biosynthesis mutants was significantly higher than that in the control (Figure 8). Therefore, we speculated that blocking the GABA metabolic shunt pathway will lead to the accumulation of ROS intermediates (Bouché et al., 2003; Fait et al., 2005), which may trigger endoreplication (Figure 9). In this hypothesis, normal GABA metabolism functioned as a signal and antioxidant to effectively inhibit the production of ROS. In the GABA biosynthetic mutants, this inhibition was relieved. The production of ROS promotes the expression of SIAMESE (SIM) and SIAMESE-RELATED (SMR) expression, of which, their encoding products inhibited kinase activity to initiate endoreplication (Figure 9). In contrast, normal GABA metabolism postponed endoreplication, and this negative regulation functions to prevent premature cell differentiation and to ensure normal leaf development. However, this conclusion must be made cautiously because, based on current data, it is difficult to demonstrate a causal relationship between GABA level and ROS in terms of triggering endoreplication during the development of Arabidopsis leaves.

Overall, the results of the present study demonstrate that the increase in polyploidy level in GABA biosynthetic mutant leaves is achieved through endoreplication, which is reflected in the increase in average cell size (Breuer et al., 2010). In this regulation, multiple regulators are involved in the initiation, maintenance, and exit of endoreplication. However, the premature termination of mitosis and the immature occurrence of endoreplication are perhaps a compensatory mechanism for leaf immature development, which resulted in increased cell ploidy. This mechanism may be mediated by ROS signalling, but the complex regulatory mechanism requires further research.

\section{Conclusion}

Using GABA biosynthetic mutants, the present study focused on the perturbation of GABA biosynthesis on endoreplication in Arabidopsis leaf development. The endoreplication cells that occurred in mutants were earlier and of higher abundance than those in the wild type. This is the reason to lead to the increase in cell size and leaf blade area. For transcription-level regulation, qRT-PCR confirmed that many genes involved in cell cycle regulation were synergistically participating in the initiation, progression, and maintenance of endoreplication. Among the regulators, SMR5, encoding protein inhibited CDK activity, was markedly upregulated in GABA biosynthetic mutants. Owing to the perturbation of GABA biosynthesis, the content of ROS increased in GABA biosynthetic mutants, which is a potential signal to trigger endoreplication in mutant leaves. Present evidence indicates that normal GABA metabolism inhibited endoreplication to prevent immature cell differentiation in leaf development. This research provides a deeper understanding of the role of GABA in plant development.

\section{Acknowledgments}




\section{Endoreplication response to GABA deficit}

384

385

386

387

We apologize if we inadvertently omitted citations of major contributions to this area. We thank Prof. Barry Shelp (University of Guelph, Canada) for generously providing the mutants seeds. We would like to thank Editage (www.editage.cn) for English language editing.

\section{$7 \quad$ Author Contributions}

YXG studied the root phenotype in relation to GABA metabolism and wrote the draft of the manuscript. HY and YX studied the role of ROS in cell-cycle regulation. GHY studied the role of small molecules in plant development and revised the manuscript.

\section{Conflict of Interest}

The authors declare that the research was conducted in the absence of any commercial or financial relationships that could be construed as a potential conflict of interest.

\section{$9 \quad$ Funding}

This work was supported by the Special Fund for Basic Scientific Research of Central Colleges, South-Central University for Nationalities (CZP17051), National Natural Science Foundation of China (31270361), studies on the regulation mechanisms of agronomic traits in important crops and $A$. thaliana supported by State Administration of Foreign Experts Affairs in Ministry of Science and Technology of the People's Republic of China (P193009007) and Fund for Key Laboratory Construction of Hubei Province (Grant No.2018BFC360).

\section{Data Availability Statement}

No datasets were generated for this study.

\section{References}

Allan WL, Simpson JP, Clark SM, Shelp BJ. Gamma-hydroxybutyrate accumulation in Arabidopsis and tobacco plants is a general response to abiotic stress: putative regulation by redox balance and glyoxylate reductase isoforms. J Exp Bot 2008; 59: $2555-64$.

Baum, G., S Lev-Yadun, S., Fridmann, Y., Arazi, T., Katsnelson, H., Zik, M., and Fromm, H. (1996). Calmodulin binding to glutamate decarboxylase is required for regulation of glutamate and GABA metabolism and normal development in plants. The EMBO J. 15, 2988-2996

Beemster GT, Vercruysse S, De VL, et al. The Arabidopsis leaf as a model system for investigating the role of cell cycle regulation in organ growth. Journal of Plant Research, 2006, 119(1):43-50. 


\section{Endoreplication response to GABA deficit}

Bouché N, Fait A, Bouchez D, Møller SG, Fromm H. Mitochondrial succinic-semialdehyde dehydrogenase of the gamma-aminobutyrate shunt is required to restrict levels of reactive oxygen intermediates in plants. Proc Natl Acad Sci USA 2003; 100:6843-8.

Boudolf V, Vlieghe K, Beemster GT, Magyar Z, Torres Acosta JA, Maes S, Van Der Schueren E, Inzé D, De Veylder L. (2004). The plant-specific cyclin-dependent kinase CDKB1;1 and transcription factor E2Fa-DPa control the balance of mitotically dividing and endoreduplicating cells in Arabidopsis. Plant Cell. 16(10):2683-2692.

Bown AW, Shelp BJ. Plant GABA: Not Just a Metabolite. Trends Plant Sci. 2016, 21(10):811-813.

Breuer C, Braidwood L, Sugimoto K. Endocycling in the path of plant development. Curr Opin Plant Biol. 2014, 17:78-85.

Breuer C, Ishida T, Sugimoto K. Developmental control of endocycles and cell growth in plants. Current Opinion in Plant Biology, 2010, 13(6):654-660.

Brikis CJ, Zarei A, Trobacher CP, DeEll JR, Akama K,Mullen RT ,Bozzo GG, Shelp BJ. Ancient Plant Glyoxylate/Succinic Semialdehyde Reductases: GLYR1s Are Cytosolic, Whereas GLYR2s Are Localized to Both Mitochondria and Plastids. Front Plant Sci. 2017; 8: 601.

Castellano MM, Boniotti MB, Caro E, et al. DNA replication licensing affects cell proliferation or endoreplication in a cell type-specific manner. The Plant cell, 2004, 16(9): 2380-93.

Castellano MM, del Pozo JC, Ramirez-Parra E, Brown S, Gutierrez C. Expression and stability of Arabidopsis CDC6 are associated with endoreplication. Plant Cell. 2001, 13(12):2671-86.

Churchman ML, Brown ML, Kato N, Kirik V, Hülskamp M, Inzé D, De Veylder L, Walker JD, Zheng Z, Oppenheimer DG, Gwin T, Churchman J, Larkin JC. SIAMESE, a plant-specific cell cycle regulator, controls endoreplication onset in Arabidopsis thaliana. Plant Cell. 2006, 18(11):3145-57. 


\section{Endoreplication response to GABA deficit}

446 Coelho, C., Dante, R. Sabelli, P., Sun, Y., Dilkes, B., Gordon-Kamm, W., and Larkins, B. (2005). Cyclin-dependent kinase inhibitors in maize endosperm and their potential role in endoreduplication. Plant Physiol. 138, 2323-2336.

Coleman ST, Fang TK, Rovinsky SA, Turano FJ, Moye-Rowley WS. Expression of a

De Veylder L, Larkin JC, Schnittger A. Molecular control and function of endoreplication in development and physiology. Trends Plant Sci. 2011,16(11):624-34.

De Veylder L., Beeckman T., Beemster G.T.S., Krols L., Terras F., Landrieu I., van der Schueren E., Maes S., Naudts M., Inze D. (2001). Functional analysis of cyclin-dependent kinase inhibitors of Arabidopsis. Plant Cell 13:1653-1667

Dewitte W, Riou-Khamlichi C, Scofield S, Healy JM, Jacqmard A, Kilby NJ, Murray JA. Altered cell cycle distribution, hyperplasia, and inhibited differentiation in Arabidopsis caused by the D-type cyclin CYCD3. Plant Cell. 2003, 15(1):79-92.

Dewitte W, Scofield S, Alcasabas AA, Maughan SC, Menges M, Braun N, Collins C, Nieuwland J, Prinsen E, Sundaresan V, Murray JA. Arabidopsis CYCD3 D-type

Dubois M, Selden K, Bediee A, et al. SIAMESE-RELATED1 Is Regulated cyclins link cell proliferation and endocycles and are rate-limiting for cytokinin Posttranslationally and Participates in Repression of Leaf Growth under Moderate Drought. Plant physiology, 2018, 176(4): 2834-50.

Fait A, Yellin A, Fromm H. GABA shunt deficiencies and accumulation of reactive oxygen intermediates: insight from Arabidopsis mutants.FEBS Lett. 2005, $579(2): 415-20$.

Fülöp K, Tarayre S, Kelemen Z, Horváth G, Kevei Z, Nikovics K, Bakó L, Brown S, Kondorosi A, Kondorosi E. Arabidopsis anaphase-promoting complexes: multiple activators and wide range of substrates might keep APC perpetually busy. Cell Cycle. 2005, 4(8):1084-92. 


\section{Endoreplication response to GABA deficit}

475

476

477

478

479

480

481

482

483

484

485

486

487

488

489

490

491

492

493

494

495

496

497

498

499

500

501

502

Fung-Uceda J, Lee K, Seo PJ, Polyn S, De Veylder L, Mas P. The Circadian Clock

Sets the Time of DNA Replication Licensing to Regulate Growth in Arabidopsis. Dev Cell. 2018, 45 (1):101-113.

Häusler RE, Ludewig F, Krueger S. Amino acids--a life between metabolism and signaling. Plant Sci. 2014, 229:225-237.

Heyman J, Polyn S, Eekhout T, De Veylder L.Tissue-Specific Control of the Endocycle by the Anaphase Promoting Complex/Cyclosome Inhibitors UVI4 and DEL1. Plant Physiol. 2017,175(1):303-313.

Jacoby RP, Taylor NL, Millar AH. The role of mitochondrial respiration in salinity tolerance. Trends Plant Sci 2011; 16:614-23.

Jun SE, Okushima Y, Nam J, Umeda M, Kim GT. Kip-related protein 3 is required for control of endoreduplication in the shoot apical meristem and leaves of Arabidopsis. Mol Cells. 2013, 35(1):47-53.

Kumar N, Harashima H, Kalve S, Bramsiepe J, Wang K, Sizani BL, Bertrand LL, Johnson MC, Faulk C, Dale R, Simmons LA, Churchman ML, Sugimoto K, Kato N, Dasanayake M, Beemster G, Schnittger A, Larkin JC. Functional Conservation in the SIAMESE-RELATED Family of Cyclin-Dependent Kinase Inhibitors in Land Plants. Plant Cell. 2015, 27(11):3065-80.

Lammens T, Li J, Leone G, et al. Atypical E2Fs: new players in the E2F transcription factor family. Trends in Cell Biology, 2009, 19(3):111-118.

Liu CL, Zhao L, Yu GH. (2011). The dominant glutamic acid metabolic influx to produce $\gamma$-amino butyric acid over proline in Nicotiana tabacum leaves under water stress relates to its significant role of antioxidant activity. Integr. Plant Biol. 53:608-618.

Masubelele NH, Dewitte W, Menges M, Maughan S, Collins C, Huntley R, Nieuwland J, Scofield S, Murray JA. D-type cyclins activate division in the root apex to promote seed germination in Arabidopsis. Proc Natl Acad Sci USA. $2005, \quad 25 ; 102(43): 15694-9$. 


\section{Endoreplication response to GABA deficit}

503

504

505

506

507

508

509

510

511

512

513

514

515

516

517

518

519

520

521

522

523

524

525

526

Matsunaga, S., Katagiri, Y., Nagashima, Y., Sugiyama, T., Hasegawa, J., Hayashi, K. and Sakamoto, T. (2013). New insights into the dynamics of plant cell nuclei and chromosomes. Int. Rev. Cell Mol. Biol. 305, 253-301.

Melaragno J E, Mehrotra B, Coleman A W. Relationship between Endopolyploidy and Cell Size in Epidermal Tissue of Arabidopsis. Plant Cell, 1993, 5(11):1661-1668

Michaeli S, Fait A, Lagor K, Nunes-Nesi A, Grillich N, Yellin A, et al. A mitochondrial GABA permease connects the GABA shunt and the TCA cycle, and is essential for normal carbon metabolism. Plant J 2011; 67:485-498.

Nowack MK, Harashima H, Dissmeyer $\mathrm{N}$, et al. Genetic framework of cyclin-dependent kinase function in Arabidopsis. Developmental cell, 2012, 22(5): 1030-40.

Palanivelu R, Brass L, Edlund AF, Preuss D. Pollen tube growth and guidance is regulated by POP2, an Arabidopsis gene that controls GABA levels. Cell. 2003, $114(1): 47-59$.

Podlešáková K, Ugena L, Spíchal L, Doležal K, De Diego N. Phytohormones and polyamines regulate plant stress responses by altering GABA pathway. New Biotechnol. 2019, 48:53-65.

Ramesh SA, Tyerman SD, Gilliham M, Xu B. $\gamma$-Aminobutyric acid (GABA) signalling in plants. Cell Mol Life Sci. 2017, 74(9):1577-1603.

Renault H, El Amrani A, Berger A, Mouille G, Soubigou-Taconnat L, Bouchereau A, et al. $\gamma$-Aminobutyric acid transaminase deficiency impairs central carbon metabolism and leads to cell wall defects during salt stress in Arabidopsis roots. Plant Cell Environ 2013; 36:1009-18.

Renault H, El Amrani A, Palanivelu R, Updegraff EP, Yu A, Renou JP, Preuss D, Bouchereau A, Deleu C. GABA accumulation causes cell elongation defects and a decrease in expression of genes encoding secreted and cell wall-related proteins in Arabidopsis thaliana.Plant Cell Physiol. 2011, 52(5):894-908. 


\section{Endoreplication response to GABA deficit}

531 Sawa S, Watanabe K, Goto K, Liu YG, Shibata D, Kanaya E, Morita EH, Okada K.

532 FILAMENTOUS FLOWER, a meristem and organ identity gene of Arabidopsis, 533 encodes a protein with a zinc finger and HMG-related domains.Genes Dev. 1999, 534 13(9):1079-88.

535 Schippers JH, Foyer CH, Van Dongen JT. Redox regulation in shoot growth, SAM 536 maintenance and flowering. Current Opinion in Plant Biology, 2016, 29:121-128.

Seifikalhor M, Aliniaeifard S, Hassani B, Niknam V \& Lastochkina O. (2019). Diverse role of $\gamma$-aminobutyric acid in dynamic plant cell responses. Plant Cell Reports. 38(8):847-867.

Siegfried KR, Eshed Y, Baum SF, Otsuga D, Drews GN, Bowman JL. Members of the YABBY gene family specify abaxial cell fate in Arabidopsis. Development. 1999, 126(18):4117-28.

Toyokura K, Hayashi M, Nishimura M, and Okada K. Adaxial-abaxial patterning: a novel function of the GABA shunt. Plant Signal Behav. 2012, 7 (7):705-7.

Toyokura K, Watanabe K, Oiwaka A, Kusano M, Tameshige T, Tatematsu K, Matsumoto N, Tsugeki R, Saito K, Okada K. Succinic semialdehyde dehydrogenase is involved in the robust patterning of Arabidopsis leaves along the adaxial-abaxial axis. Plant Cell Physiol. 2011, 52(8):1340-53.

Umeda M, Aki SS, Takahashi N. Gap 2 phase: making the fundamental decision to

Verkest A, Manes CL, Vercruysse S, Maes S, Van Der Schueren E, Beeckman T, Genschik P, Kuiper M, Inzé D, De Veylder L (2005). The cyclin-dependent kinase inhibitor KRP2 controls the onset of the endoreduplication cycle during Arabidopsis leaf development through inhibition of mitotic CDKA; 1 kinase 


\section{Endoreplication response to GABA deficit}

Watkins JM, Chapman JM, Muday GK (2017). Abscisic Acid-Induced Reactive Oxygen Species Are Modulated by Flavonols to Control Stomata Aperture. Plant Physiol. 175(4):1807-1825.

Yang K, Wang H, Xue S, et al. Requirement for A-type cyclin-dependent kinase and cyclins for the terminal division in the stomatal lineage of Arabidopsis. J Exp Bot, 2014, 65(9): 2449-2461.

Yi D, Alvim Kamei CL, Cools T, Vanderauwera S, Takahashi N, Okushima Y, Eekhout T, Yoshiyama KO, Larkin J, Van den Daele H, Conklin P, Britt A, Umeda M, De Veylder L. The Arabidopsis SIAMESE-RELATED cyclin-dependent kinase inhibitors SMR5 and SMR7 regulate the DNA damage checkpoint in response to reactive oxygen species. Plant Cell. 2014, 26(1):296-309.

\section{Figure Legends}

Figure 1. Leaf area of $\gamma$-Aminobutyric acid (GABA) biosynthetic mutants was larger than that of wild-type Arabidopsis.

Top view of leaves at $8 \mathrm{~d}$ after stratification of A. wild type; B. gad1 mutant, C. gad2 mutant and D. gadl/gad2 mutants; E. Leaf growth curve of GABA mutants and wild type of Arabidopsis in the early stage (from 4-8 d after stratification). Results are presented as averages \pm SE of three separate experiments $(n=15)$. Bar in A-D $=860$ $\mu \mathrm{m}$.

Figure 2. Epidermal cell size in the first true leaves of $\gamma$-Aminobutyric acid (GABA) biosynthetic mutants was larger than that of wild-type Arabidopsis at the early growth stage.

Epidermal cell of A. wild type; B. gad1 mutant, C. gad2 mutant and D. gad1/gad2 mutants; E. Cell size comparison among GABA mutants and wild type of Arabidopsis in the early stage (7-9 d after stratification). Results are presented as averages $\pm \mathrm{SE}$ of 60 cells calculated across three separate experimental replicates. Asterisks represent significant differences between the mutants and the wild type $(P<0.05)$ and were determined using one-way ANOVA. Bar in A-D $=55 \mu \mathrm{m}$.

Figure 3. Octoploid (8n) cells occurred earlier in biosynthetic mutants than that in the wild type. Top panel: DNA ploidy analysis in leaf early growth stage (7-8 days after stratification) between $\gamma$-Aminobutyric acid (GABA) biosynthetic mutants and the wild type. Left bottom panel: DNA ploidy analysis in leaf middle-late stage (21 days after stratification) between GABA mutants and the control. Right bottom panel: $8 \mathrm{C}$ percentage comparison among mutants and the wild type during the long growth period. 


\section{Endoreplication response to GABA deficit}

Figure 4. Expression of Cyclin D components in biosynthetic mutants was lower than that in the wild type at the $8^{\text {th }}$ day after stratification. Results are presented as averages \pm SE of triplicate experiments. Asterisks represent significant differences between the mutants and the wild type $(* P<0.05 ; * * P<0.01)$ and were determined using one-way ANOVA.

Figure 5. Expression of $C D A ; 1$ and $E 2 F a$ in biosynthetic mutants was lower than that in the wild type at the $8^{\text {th }}$ day after stratification. Results are presented as averages \pm $\mathrm{SE}$ of three independent experimental replicates. Asterisks represent significant differences between the mutants and the wild type $(* P<0.05$; ** $P<0.01)$ and were determined using one-way ANOVA.

Figure 6. Expression of CCS52A and CDC6 in biosynthetic mutants was higher than that in the wild type at the $8^{\text {th }}$ day after stratification. Results are presented as averages $\pm \mathrm{SE}$ of three independent experimental replicates. Asterisks represent significant differences between the mutants and the wild type $\left({ }^{*} P<0.05\right.$; $\left.* * P<0.01\right)$ and were determined using one-way ANOVA.

Figure 7. Expression of SIAMESE (SIM) and SIAMESE-RELATED (SMR) components in biosynthetic mutants was higher than that in the wild type at the $8^{\text {th }}$ day after stratification. Results are presented as averages \pm SE of three independent experimental replicates. Asterisks represent significant differences between the mutants and the wild type $(* P<0.05 ; * * P<0.01)$. Statistics were determined using one-way ANOVA.

Figure 8. Reactive oxygen species (ROS) level in guard cells (GCs) of $\gamma$-Aminobutyric acid (GABA) mutants are higher than that of control A-D. DCF fluorescence (green) in epidermal GCs of GABA biosynthetic mutants and wild type Arabidopsis. E. DCF fluorescence was quantified in the mutants and control. Results are presented as averages $\pm \mathrm{SE}$ of three separate experiments $(\mathrm{n}=16)$. Asterisks represent significant differences between the mutant and the wild type $(P<0.05)$ and were determined using one-way ANOVA. Bar in A-D $=55 \mu \mathrm{m}$.

Figure 9. Working hypothesis of $\gamma$-Aminobutyric acid (GABA) negatively control the endoreplication of Arabidopsis leaves.

GABA, as a normal metabolic signal and antioxidant, effectively inhibits reactive oxygen species (ROS) production. In the GABA biosynthetic mutants, owing to biosynthetic perturbation, the inhibition of GABA on ROS was relieved. The production of ROS promotes the expression of SIAMESE (SIM) and SIAMESE-RELATED (SMR). Both components are inhibitors of Cyclin-dependent Kinase complexes (e.g. CYC3;1-CDKA;1), and low levels of kinases initiate endoreplication in Arabidopsis. Other components, such as CDC6, synergistically respond to low levels of GABA to prime endoreplication. In the wild type, the normal metabolism of GABA delays endoreplication and prevents premature endoreplication.

\section{Supporting Materials}

Table S1. The primers of the genes involved in cell cycle regulation, endocycle initiation, progression, and exit.

Figure S1. The $\gamma$-Aminobutyric acid (GABA) analysis was performed on whole-shoot samples. Results are presented as averages \pm standard error (SE) of three independent 


\section{Endoreplication response to GABA deficit}

639 replicates. Significant differences from the control are indicated with asterisks: ${ }^{*} P$ $640<0.05, * * P<0.01$, by one-way ANOVA. 


\section{Endoreplication response to GABA deficit}

642

643

644
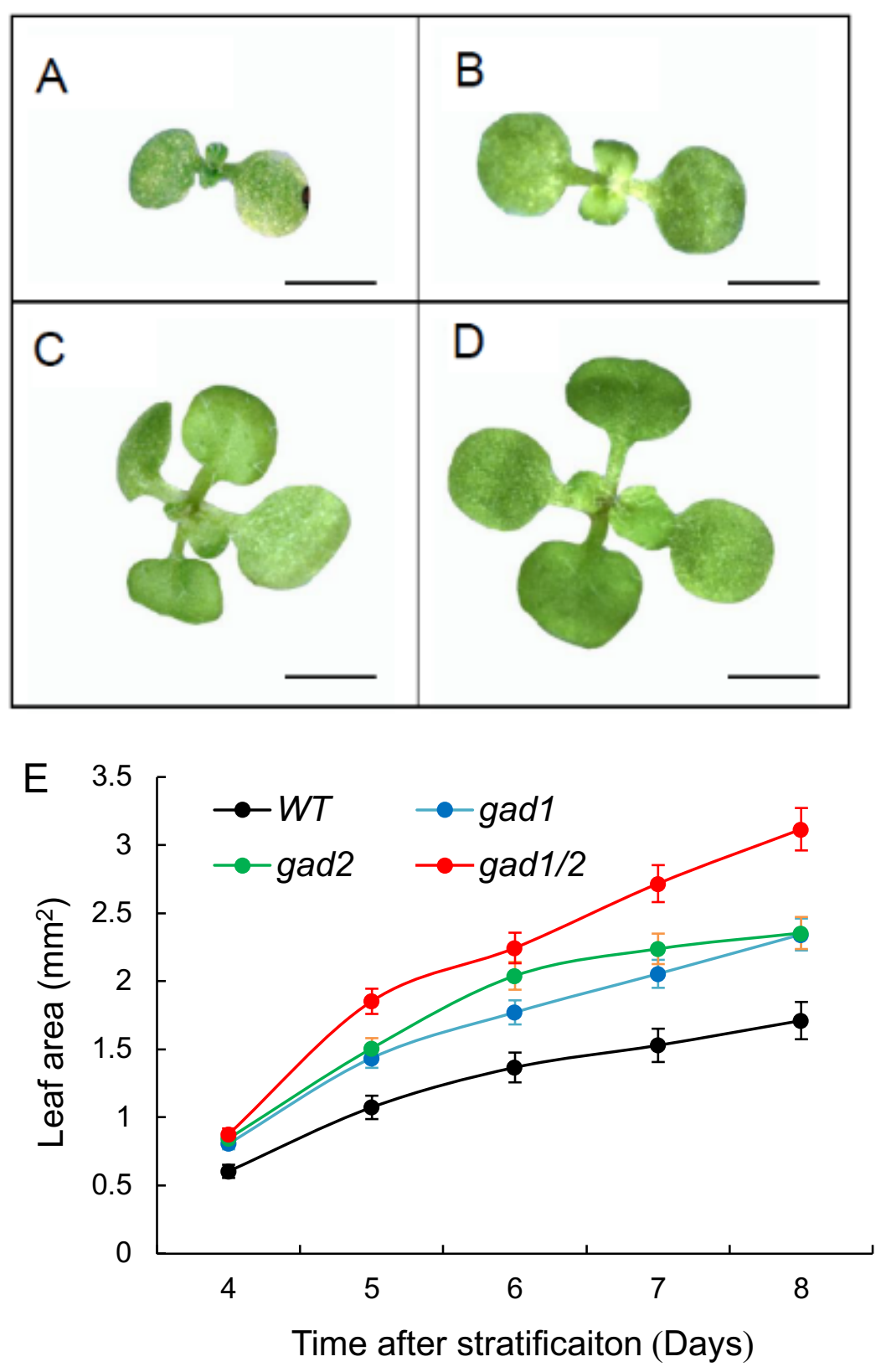

646 Figure 1. Leaf area of $\gamma$-Aminobutyric acid (GABA) biosynthetic mutants was larger 647 than that of wild-type Arabidopsis.

648 Top view of leaves at $8 \mathrm{~d}$ after stratification of A. wild type; B. gad1 mutant, C. gad2 649 mutant and D. gadl/gad2 mutants; E. Leaf growth curve of GABA mutants and wild 650 type of Arabidopsis in the early stage (from 4-8 d after stratification). Results are 651 presented as averages \pm SE of three separate experiments $(n=15)$. Bar in $A-D=860$ $652 \mu \mathrm{m}$. 


\section{Endoreplication response to GABA deficit}

654

655
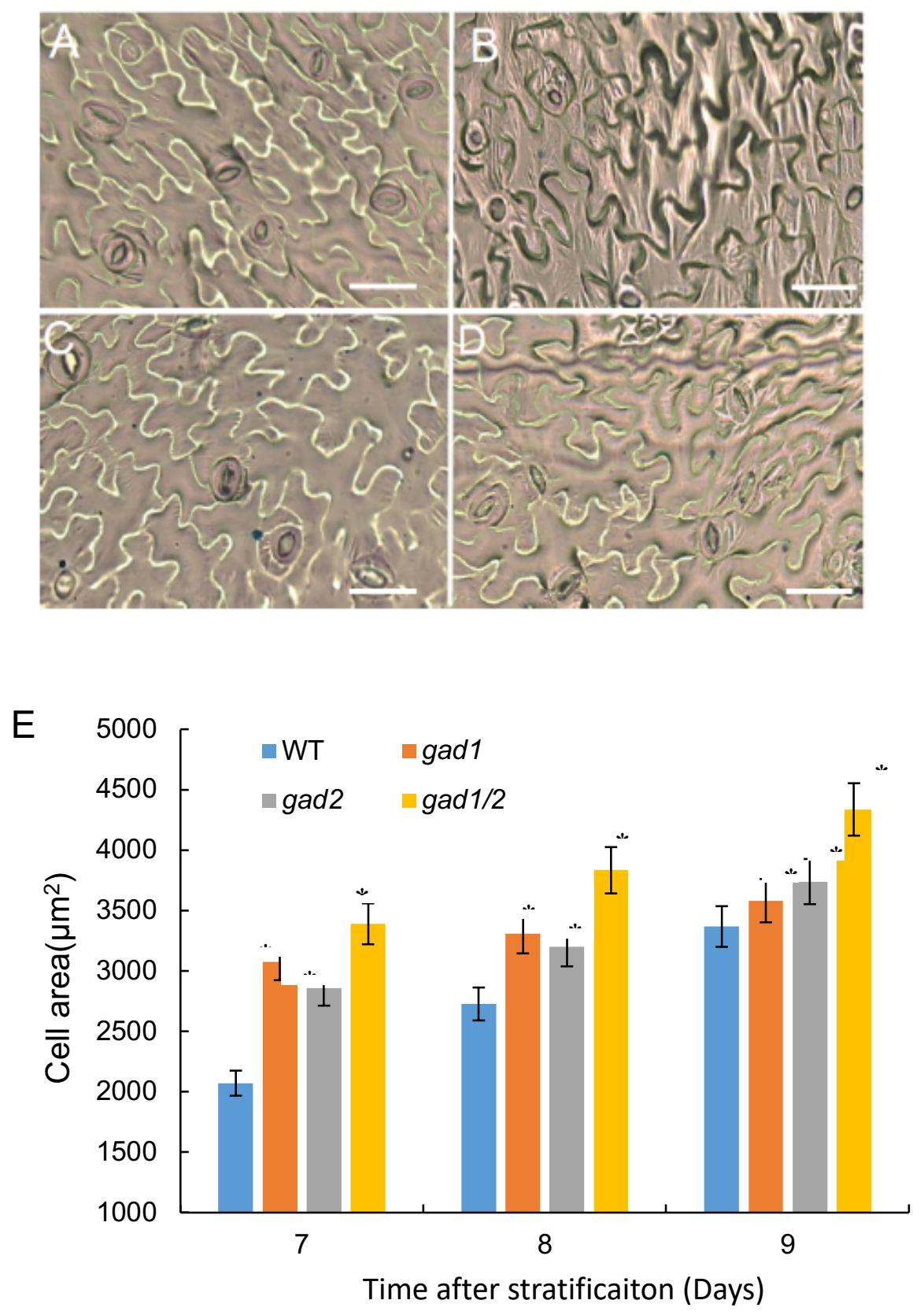

658 Figure 2. Epidermal cell size in the first true leaves of $\gamma$-Aminobutyric acid (GABA) 659 biosynthetic mutants was larger than that of wild-type Arabidopsis at the early growth 660 stage.

661 Epidermal cell of A. wild type; B. gad1 mutant, C. gad2 mutant and D. gad1/gad2 662 mutants; E. Cell size comparison among GABA mutants and wild type of Arabidopsis 663 in the early stage (7-9 d after stratification). Results are presented as averages \pm SE of 66460 cells calculated across three separate experimental replicates. Asterisks represent 


\section{Endoreplication response to GABA deficit}

665 significant differences between the mutants and the wild type $(P<0.05)$ and were 666 determined using one-way ANOVA. Bar in A-D $=55 \mu \mathrm{m}$.

667
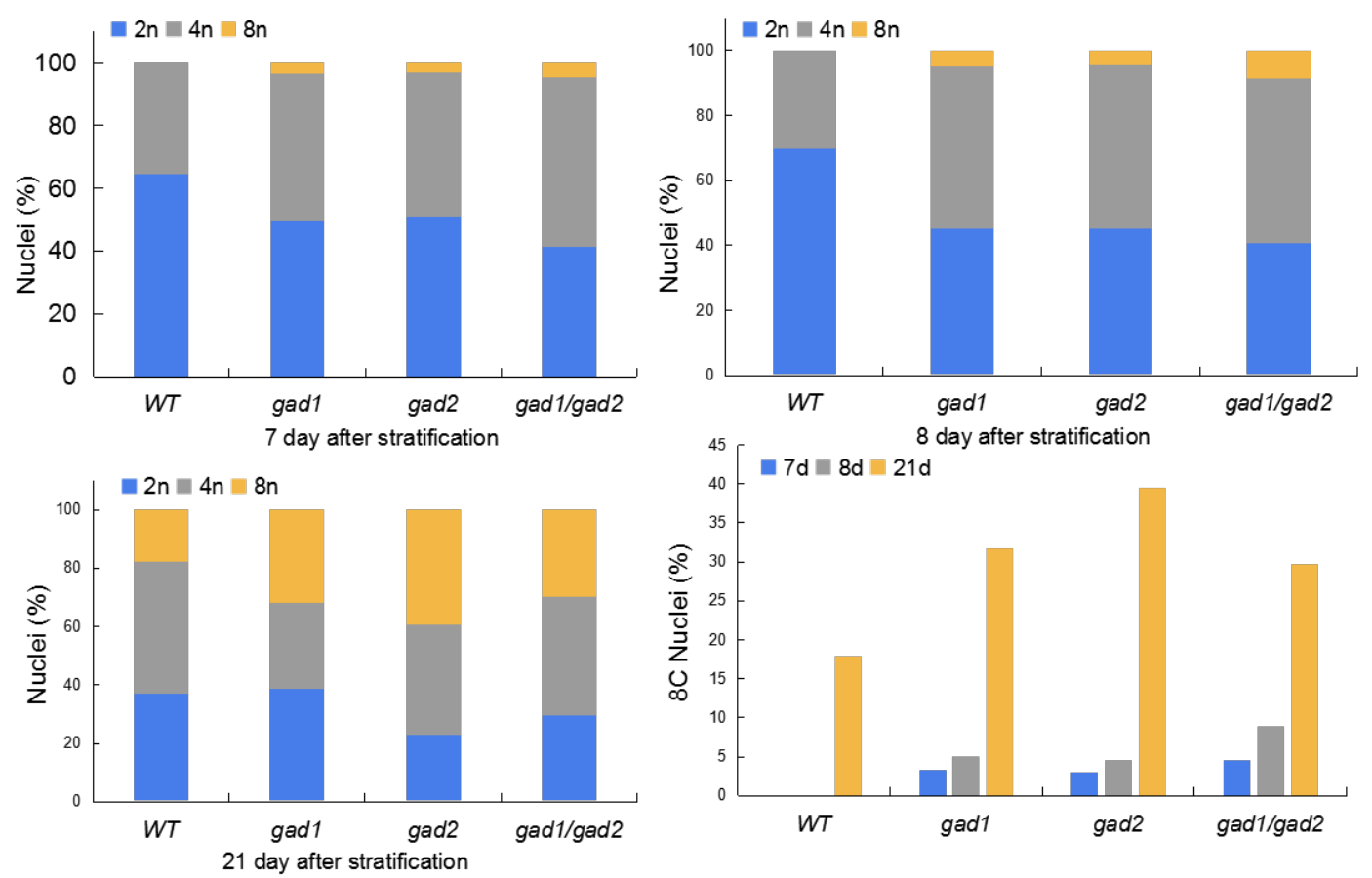

669 Figure 3. Octoploid (8n) cells occurred earlier in biosynthetic mutants than that in the 670 wild type. Top panel: DNA ploidy analysis in leaf early growth stage (7-8 days after 671 stratification) between $\gamma$-Aminobutyric acid (GABA) biosynthetic mutants and the 672 wild type. Left bottom panel: DNA ploidy analysis in leaf middle-late stage (21 days 673 after stratification) between GABA mutants and the control. Right bottom panel: 8C 674 percentage comparison among mutants and the wild type during the long growth 675 period. 


\section{Endoreplication response to GABA deficit}

678

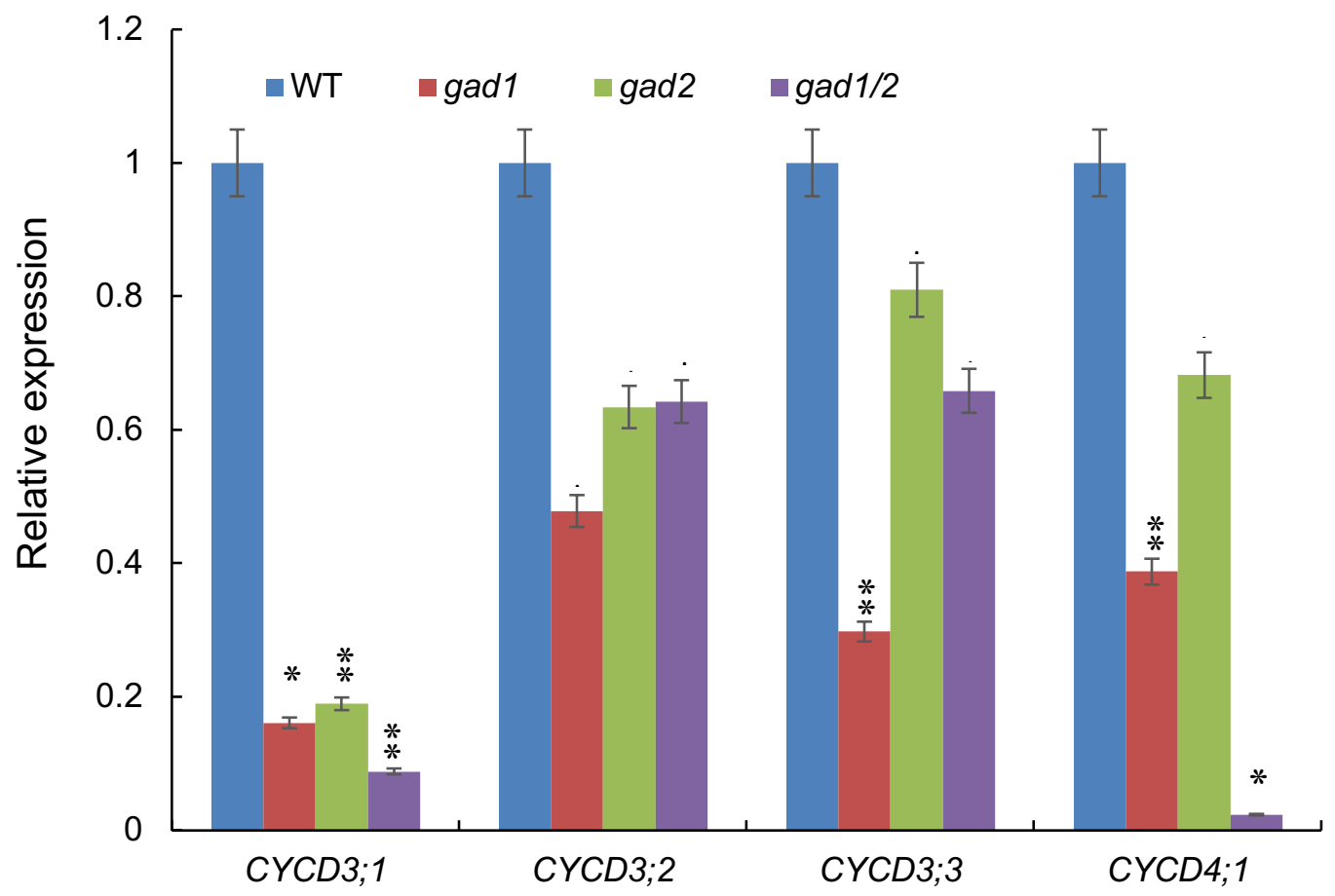

680 Figure 4. Expression of Cyclin D components in biosynthetic mutants was lower than 681 that in the wild type at the $8^{\text {th }}$ day after stratification. Results are presented as averages $682 \pm$ SE of triplicate experiments. Asterisks represent significant differences between the 683 mutants and the wild type $\left({ }^{*} P<0.05\right.$; ** $\left.P<0.01\right)$ and were determined using 684 one-way ANOVA. 


\section{Endoreplication response to GABA deficit}

686

687

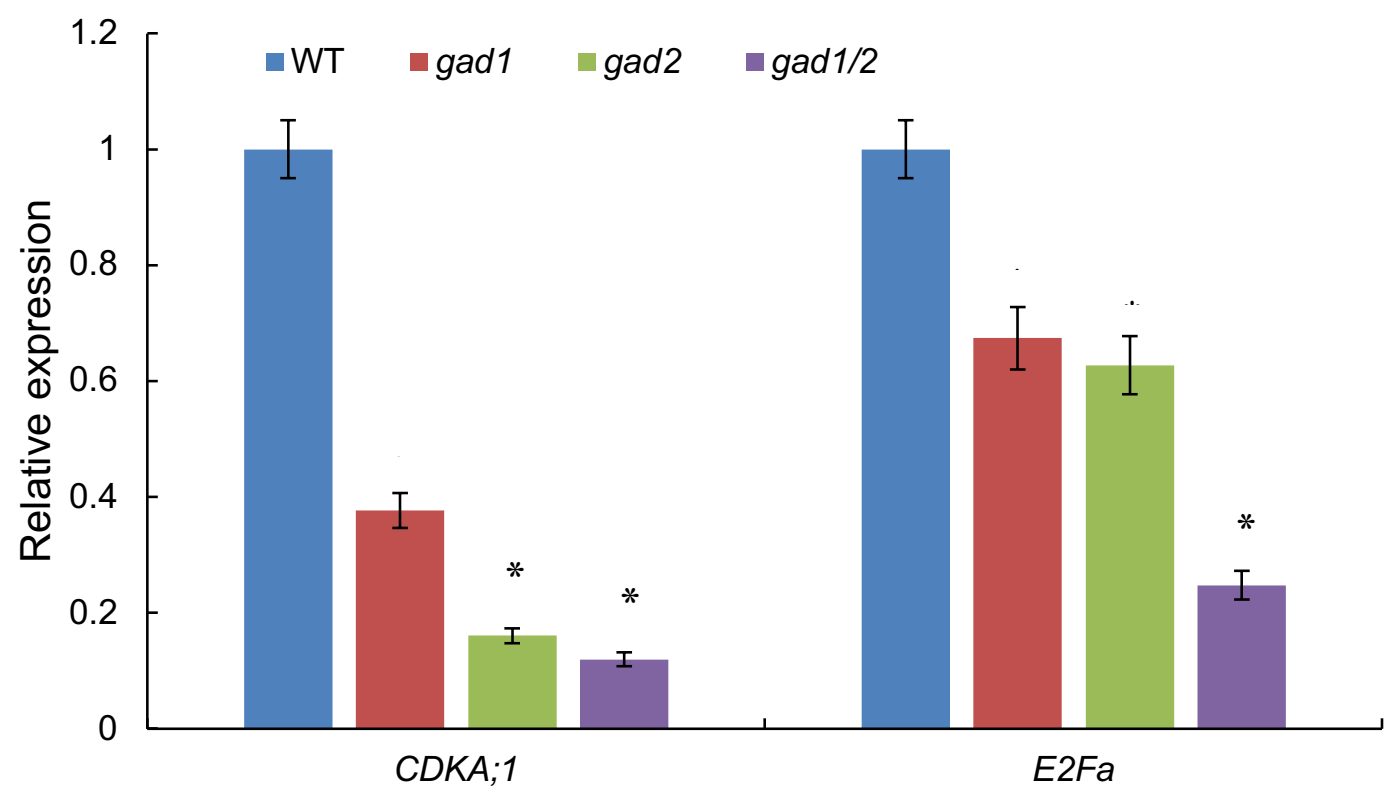

688

689 Figure 5. Expression of $C D A ; 1$ and $E 2 F a$ in biosynthetic mutants was lower than that 690 in the wild type at the $8^{\text {th }}$ day after stratification. Results are presented as averages \pm 691 SE of three independent experimental replicates. Asterisks represent significant 692 differences between the mutants and the wild type $(* P<0.05 ; * * P<0.01)$ and were 693 determined using one-way ANOVA. 


\section{Endoreplication response to GABA deficit}

695

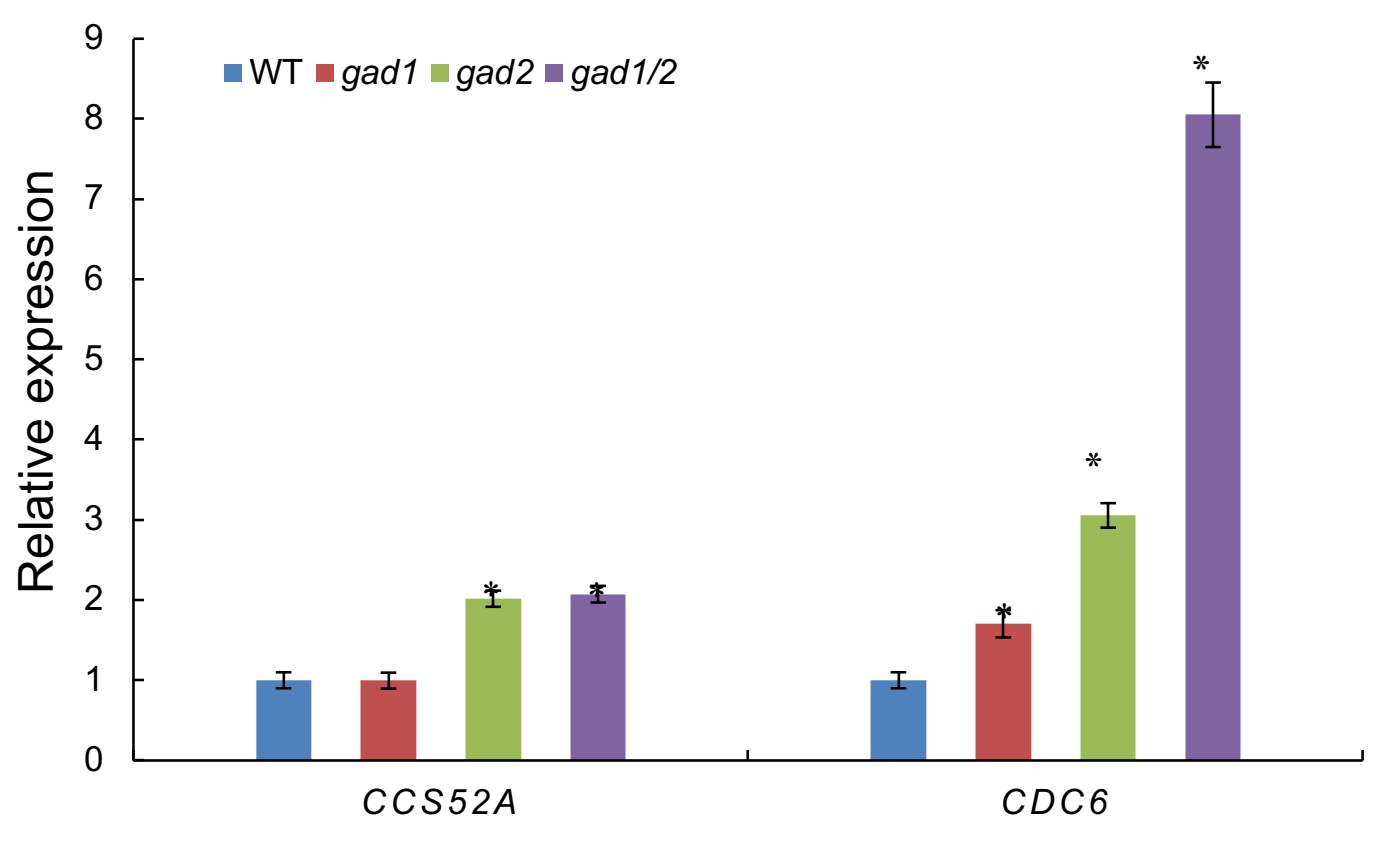

Figure 6. Expression of CCS52A and CDC6 in biosynthetic mutants was higher than that in the wild type at the $8^{\text {th }}$ day after stratification. Results are presented as averages \pm SE of three independent experimental replicates. Asterisks represent significant differences between the mutants and the wild type $\left({ }^{*} P<0.05\right.$; $\left.* * P<0.01\right)$ and were determined using one-way ANOVA. 


\section{Endoreplication response to GABA deficit}

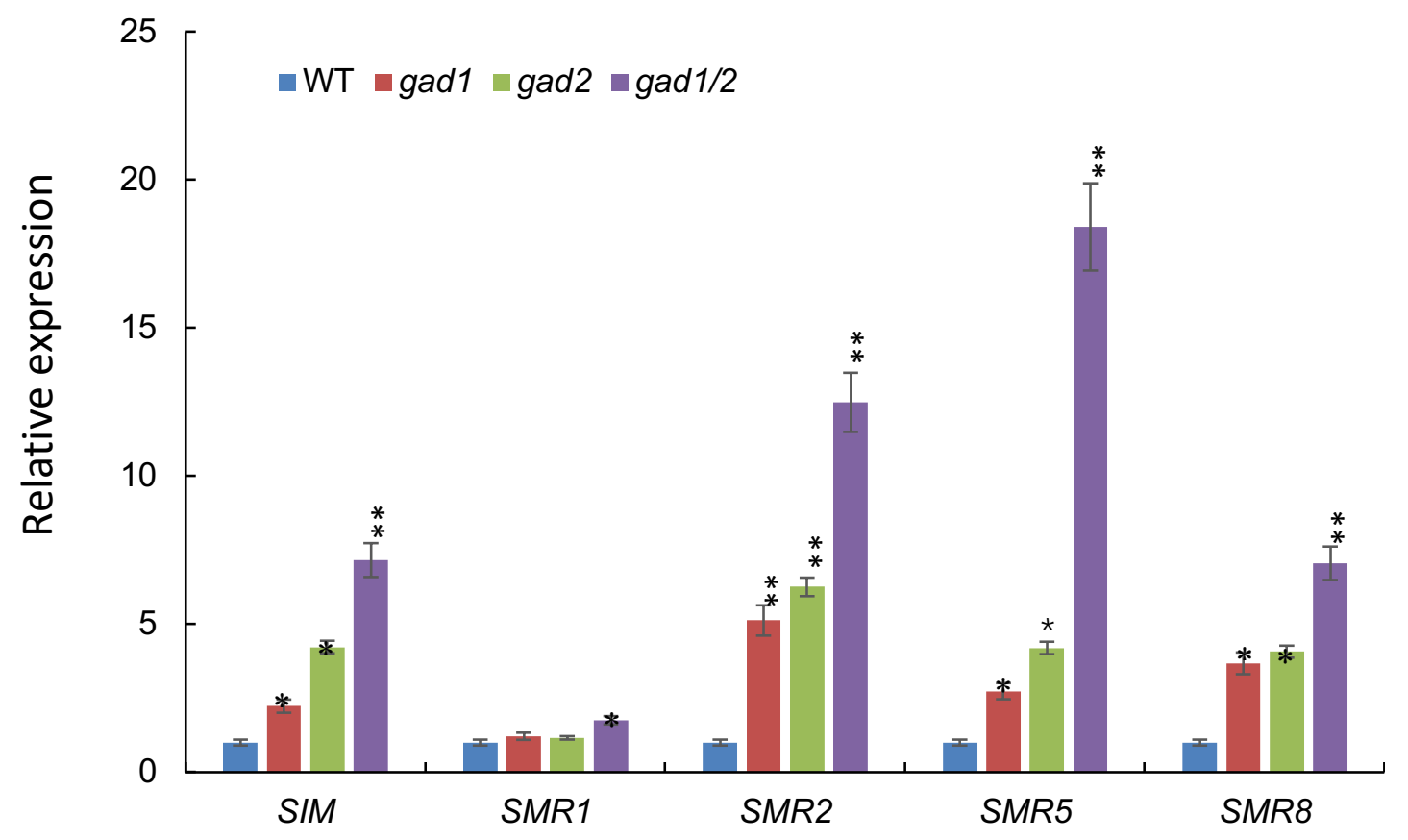

708 Figure 7. Expression of SIAMESE (SIM) and SIAMESE-RELATED (SMR) 709 components in biosynthetic mutants was higher than that in the wild type at the $8^{\text {th }}$ 710 day after stratification. Results are presented as averages \pm SE of three independent 711 experimental replicates. Asterisks represent significant differences between the 712 mutants and the wild type $\left({ }^{*} P<0.05 ; * * P<0.01\right)$. Statistics were determined using 713 one-way ANOVA. 


\section{Endoreplication response to GABA deficit}

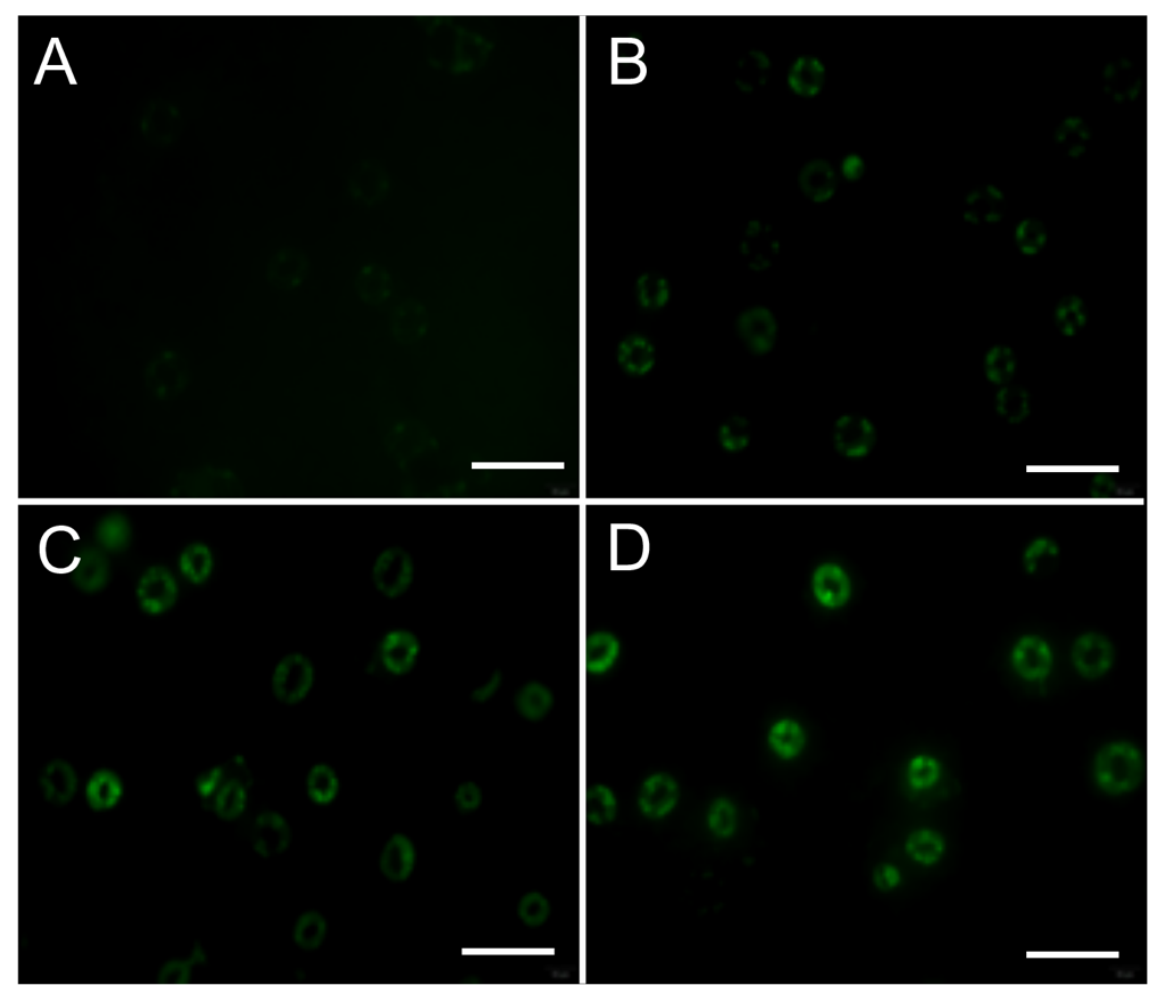

716

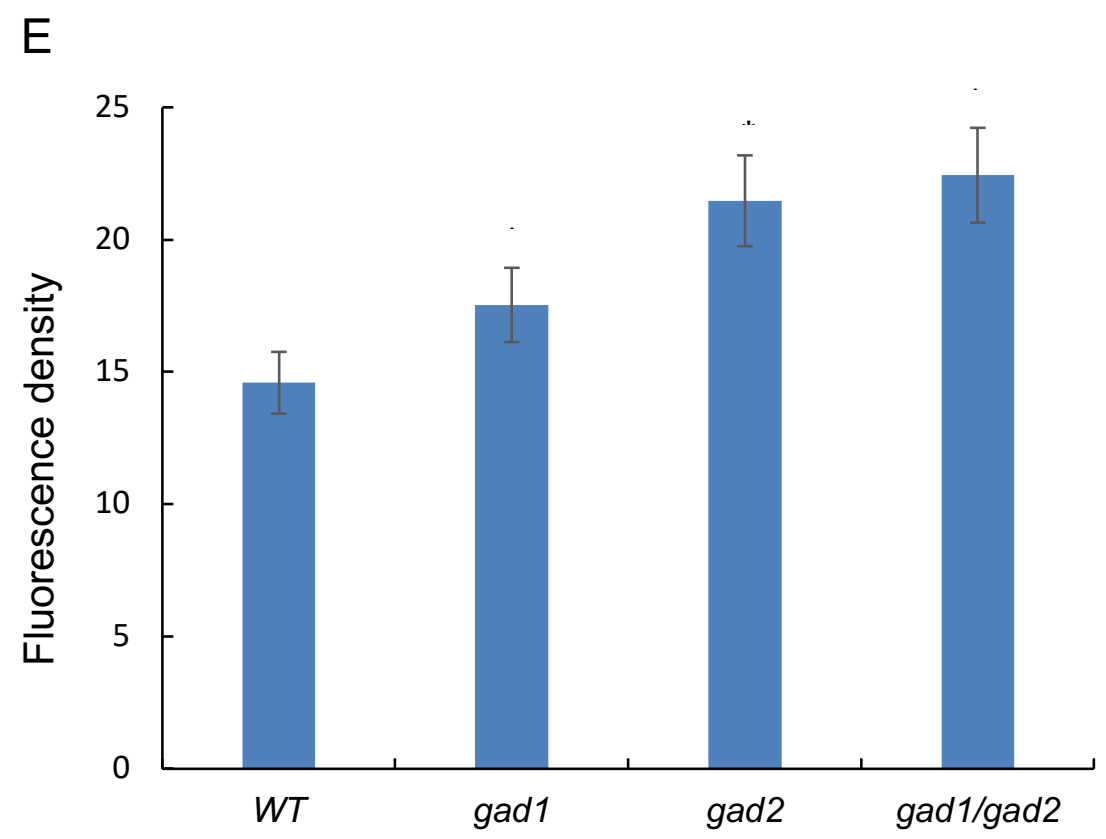

718 Figure 8. Reactive oxygen species (ROS) level in guard cells (GCs) of $719 \gamma$-Aminobutyric acid (GABA) mutants are higher than that of control A-D. DCF 720 fluorescence (green) in epidermal GCs of GABA biosynthetic mutants and wild type 721 Arabidopsis. E. DCF fluorescence was quantified in the mutants and control. Results 722 are presented as averages \pm SE of three separate experiments $(n=16)$. Asterisks 


\section{Endoreplication response to GABA deficit}

723 represent significant differences between the mutant and the wild type $(P<0.05)$ and

724 were determined using one-way ANOVA. Bar in A-D $=55 \mu \mathrm{m}$.

725 


\section{Endoreplication response to GABA deficit}
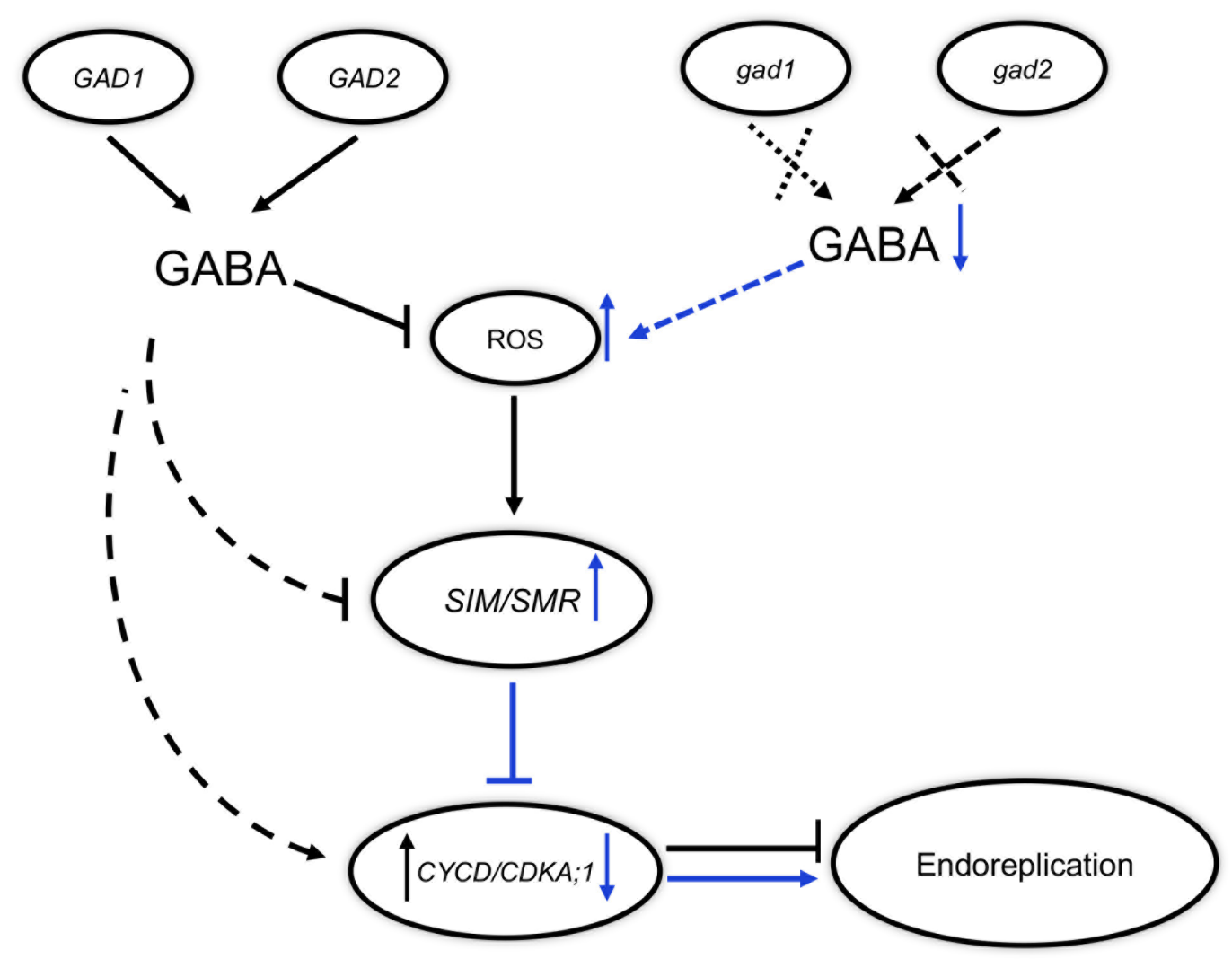

Figure 9. Working hypothesis of $\gamma$-Aminobutyric acid (GABA) negatively control the endoreplication of Arabidopsis leaves.

731 GABA, as a normal metabolic signal and antioxidant, effectively inhibits reactive oxygen species (ROS) production. In the GABA biosynthetic mutants, owing to biosynthetic perturbation, the inhibition of GABA on ROS was relieved. The production of ROS promotes the expression of SIAMESE (SIM) and SIAMESE-RELATED (SMR). Both components are inhibitors of Cyclin-dependent Kinase complexes (e.g. CYC3;1-CDKA;1), and low levels of kinases initiate endoreplication in Arabidopsis. Other components, such as CDC6, synergistically respond to low levels of GABA to prime endoreplication. In the wild type, the normal metabolism of GABA delays endoreplication and prevents premature endoreplication. 


\section{Endoreplication response to GABA deficit}

\section{Supporting Materials}

744 Table S1: The primers of the genes involved in cell cycle regulation, endocycle

745 initiation, progression and exit.

\begin{tabular}{|c|c|c|c|}
\hline Locus tag & Gene name & Primer & Primer sequences \\
\hline \multirow{3}{*}{ AT3G02780 } & & IPP2_EXP_F & CATGCGACACACCAACACCA \\
\hline & $I P P 2$ & & \\
\hline & & IPP2_EXP_R & TGAGGCGAATCAATGGGAGA \\
\hline \multirow{3}{*}{ AT4G34160 } & & CYCD3;1_EXP_F & CCTCTCTGTAATCTCCGATTC \\
\hline & CYCD3;1 & & \\
\hline & & CYCD3;1_EXP_R & AAGGACACCGAGGAGATTAG \\
\hline \multirow{3}{*}{ AT5G67260 } & & CYCD3;2_EXP_F & TCTCAGCTTGTTGCTGTGGCTTC \\
\hline & $C Y C D 3 ; 2$ & & \\
\hline & & CYCD3;2_EXP_R & TCTTGCTTCTTCCACTTGGAGGTC \\
\hline \multirow{3}{*}{ AT3G50070 } & & CYCD3;3_EXP_F & TCCGATCGGTGTGTTTGATGCG \\
\hline & $C Y C D 3 ; 3$ & & \\
\hline & & CYCD3;3_EXP_R & GCAGACACAACCCACGACTCATTC \\
\hline \multirow{3}{*}{ AT5G65420 } & & CYCD4;1_EXP_F & GAAGGAGAAGCAGCATTTGCCAAG \\
\hline & CYCD4;1 & & \\
\hline & & CYCD4;1_EXP_R & ACTGGTGTACTTCACAAGCCTTCC \\
\hline \multirow{3}{*}{ AT4G11920 } & & CCS52A2_EXP_F & CGTAGATACCAACAGCCAGGTGTG \\
\hline & CCS52A2 & & \\
\hline & & CCS52A2_EXP_R & CGTGTGTGCTCACAAGCTCATTC \\
\hline \multirow{3}{*}{ AT2G29680 } & & CDC6_EXP_F & AGGCTCTATGTGTCTGCAGGAG \\
\hline & CDC6 & & \\
\hline & & CDC6_EXP_R & ACCACTTGACACTCTGGAACTGG \\
\hline \multirow{3}{*}{ AT2G31270 } & & CDT1a_EXP_F & AATCGCTCTTCGGAAAGTGTTTCG \\
\hline & CDTla & & \\
\hline & & CDT1a_EXP_R & СCTCTGGAACTTCATCACCCTGAG \\
\hline \multirow{3}{*}{ AT3G48750 } & & CDKA;1_EXP_F & ACTGGCCAGAGCATTCGGTATC \\
\hline & $C D K A ; 1$ & & \\
\hline & & CDKA;1_EXP_R & TCGGTACCAGAGAGTAACAACCTC \\
\hline AT2G36010 & $E 2 F a$ & E2Fa_EXP_F & TAGATCGGGAGGAAGATGCTGTCG \\
\hline
\end{tabular}




\section{Endoreplication response to GABA deficit}

\begin{tabular}{|c|c|c|c|}
\hline & & E2Fa_EXP_R & TTGTCGCCTTTCTCTTTCGTGAAG \\
\hline \multirow{3}{*}{ AT2G23430 } & & KRP1_EXP_F & ACGGAGCCGGAGAATTGTTTATG \\
\hline & $K R P 1$ & & \\
\hline & & KRP1_EXP_R & CGAAACTCCATTATCACCGACGAC \\
\hline \multirow{3}{*}{ AT3G50630 } & & KRP2_EXP_F & TAGGAGATTATGGCGGCGGTTAGG \\
\hline & $K R P 2$ & & \\
\hline & & KRP2_EXP_R & TTTCACCGTCGTCGTCGTAACTC \\
\hline \multirow{3}{*}{ AT2G32710 } & & KRP4_EXP_F & AAGCTTCAACAGGACCACAAGGG \\
\hline & KRP4 & & \\
\hline & & KRP4_EXP_R & GGGTTGTCATGATTTCAGGCCTTC \\
\hline \multirow{3}{*}{ AT1G49620 } & & KRP7_EXP_F & GAGGCTCATGAAATCTCCGAAACC \\
\hline & KRP7 & & \\
\hline & & KRP7_EXP_R & CCGAGTCCATTTCTGCTGTTTCTC \\
\hline \multirow{3}{*}{ AT5G04470 } & & SIM_EXP_F & AGCCATCAAGATCCGAGCCAAC \\
\hline & $S I M$ & & \\
\hline & & SIM_EXP_R & TTGTGGTCGGAAGAAGTGGGAGTG \\
\hline \multirow{3}{*}{ AT3G10525 } & & SMR1_EXP_F & CAAAGAAGGACGAAGGTGATGACG \\
\hline & SMR1 & & \\
\hline & & SMR1_EXP_R & TGTTCTTGGGATGTGGGTGTGC \\
\hline \multirow{3}{*}{ AT1G60783 } & & SMR2_EXP_F & TCACAAGATTCCGGAGGTGGAGAC \\
\hline & SMR2 & & \\
\hline & & SMR2_EXP_R & ATCTCACGCGGTCGCTTTCTTG \\
\hline \multirow{3}{*}{ AT1G07500 } & & SMR5_EXP_F & ACGCCTACACGTGATGATTGCC \\
\hline & SMR5 & & \\
\hline & & SMR5_EXP_R & TATCCCTTCTTCGGTGGTTCCC \\
\hline \multirow{3}{*}{ AT1G10690 } & & SMR8_EXP_F & GCGGTTTCCGTCAGAATTCCAAG \\
\hline & SMR8 & & \\
\hline & & SMR8_EXP_R & GCACTTCAACGACGGTTTACGC \\
\hline
\end{tabular}

746 


\section{Endoreplication response to GABA deficit}

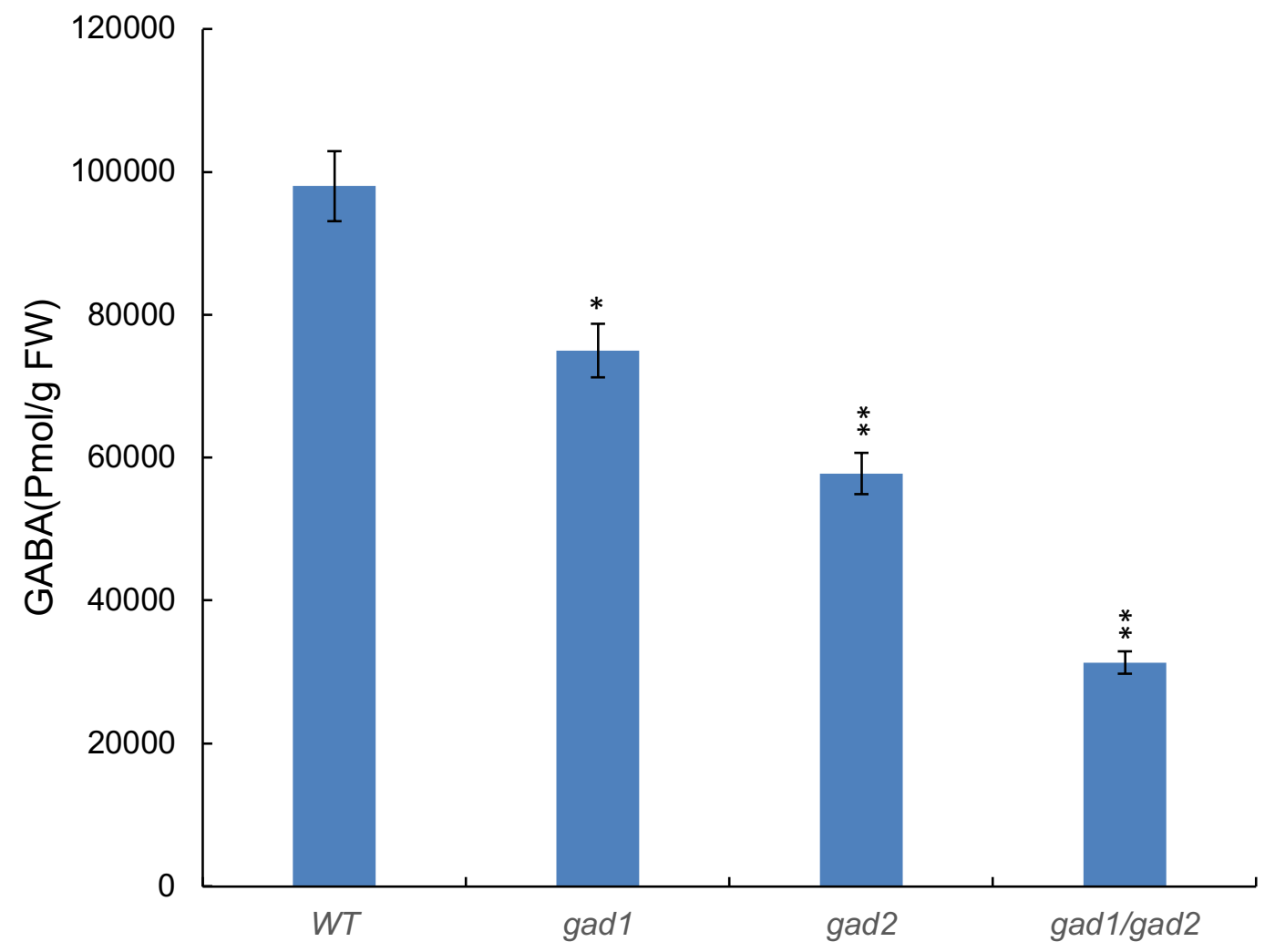

Figure S1: GABA analysis was performed on whole shoot samples. Avarages \pm standard error (SE) of three independent replicates. Significant differences from the control are indicated with asterisks: $* P<0.05$, ** $P<0.01$, by one-way ANOVA.

GABA levels in the leaves of the mutants were determined essentially as described earlier (Allan and Shelp 2006).

Allan WL, Simpson JP, Clark SM, Shelp BJ. Gamma-hydroxybutyrate accumulation in Arabidopsis and tobacco plants is a general response to abiotic stress: putative regulation by redox balance and glyoxylate reductase isoforms. J Exp Bot 2008; 59: 2555-64. 